\title{
Spatial risk assessment of livestock exposure to pumas in Patagonia, Argentina
}

\author{
W. Daniel Kissling, Néstor Fernández and José M. Paruelo
}

W. D. Kissling, Dept of Ecological Modelling, UFZ - Helmholtz Centre for Environmental Research, PO-Box 500136, DE-04301 Leipzig, Germany. (Present address of W. D. K.: Ecology, Behavior and Evolution Section, Div. of Biological Sciences, Univ. of California, San Diego, 9500 Gilman Drive, MC 0116, La Jolla, CA 92093, USA.) - N. Fernández (nestor@ebd.csic.es), Dept of Ecological Modelling, UFZ Helmholtz Centre for Environmental Research, PO-Box 500136, DE-04301 Leipzig, German. (Present address of N. F.: Dept of Conservation Biology, Doñana Biological Station, CSIC, Av. Maria Luisa s.n., ES-41013 Sevilla, Spain.) - J. M. Paruelo, Laboratorio de Análisis Regional y Teledetección, IFEVA and Facultad de Agronomía, Univ. de Buenos Aires-CONICET, San Martín 4453 (C1417DSE), Buenos Aires, Argentina.

\begin{abstract}
Livestock predation and associated human-carnivore conflicts are increasing worldwide and require the development of methods and concepts for risk assessment and conflict management. Here we use knowledge on habitat preference and distribution of pumas and provide a first assessment of the spatial risk of livestock to puma depredation in Patagonian ranches, Argentina. In an initial step, we developed a rule-based habitat model in a Geographic Information System (GIS) to predict the distribution of puma habitat at a regional scale in Patagonia. We then used empirically derived puma occurrence records from Patagonian ranches 1) to test our regional habitat predictions, and 2) to evaluate if paddock characteristics (vegetation cover, topography, and distance to roads) contribute to explain puma occurrences within ranches. Finally, we simulated three livestock management scenarios differing in their spatial and seasonal allocation of livestock to paddocks, and compared the likelihood of livestock exposure to pumas among scenarios. At a regional scale, $22 \%$ of the study region was predicted to be suitable for puma home ranges. The greatest uncertainty in these predictions resulted from assumptions on woody vegetation cover requirements at the home range scale. Within ranches, puma occurrences were positively associated with paddock topography, woody vegetation cover on paddocks, and proximity to predicted regional puma habitat. Comparing the risk of predation by puma among simulated livestock management scenarios implied that rotating livestock during seasons may help to reduce the likelihood of livestock exposure to pumas. Our results show the usefulness of rule-based habitat models for describing broad-scale carnivore distributions and for aiding risk assessments to mitigate conflicts between predators and human activities.
\end{abstract}

Conservation biologists and resource managers are increasingly raising alarms over the dimension of conflicts between humans and mammalian carnivores (Treves and Karanth 2003a, b, Graham et al. 2005, Packer et al. 2005). This conflict arises because large carnivores prey on livestock (Stahl et al. 2001, Graham et al. 2005) and occasionally threaten human safety (Packer et al. 2005). The frequency of conflicts has grown in recent decades, mainly due to the recovery of many large-carnivore populations from past extirpation efforts and the expansion of human populations into remote carnivore habitats (Stahl et al. 2001, Treves and Karanth 2003b, Packer et al. 2005). In many cases people respond by poisoning, shooting, and trapping carnivores, techniques that may kill non-target animals in high proportions. Growing public concern about lethal control operations and reasonable scientific scepticism about their effectiveness has led to the promotion of non-lethal management methods (Treves and Karanth 2003a, b).
A fundamental first step for risk assessment is the identification of areas of conflict. In turn, this can help focus interventions and develop livestock management strategies that prevent humans and carnivores from co-occurring in a given area (Treves and Karanth 2003a, b, Treves et al. 2004, Packer et al. 2005). To identify such conflictive areas requires a spatially explicit map of carnivore distribution (Treves et al. 2004). A wide variety of habitat modelling techniques have been developed which usually combine species occurrence data (e.g. from sightings or telemetry data), Geographic Information Systems (GIS), and multivariate statistical tools to formalize the link between species and their habitat (Mladenoff et al. 1995, Schadt et al. 2002b, Fernández et al. 2003, Johnson et al. 2004). However, these methods usually rely on large datasets, which are seldom available in conservation and regional planning. An alternative approach used for habitat prediction is rule-based modelling, which is especially useful 
when empirical information is limited (Starfield 1990). In these models, rules are derived from the literature or expert opinions, and are then implemented into a GIS to simulate habitat distribution. Rule-based habitat models have been developed to guide conservation management strategies for recovery assessment of the Eurasian lynx Lynx lynx (Schadt et al. 2002a) and a risk assessment of wild boar Sus scrofa reintroduction plans (Fernández et al. 2006).

We focused on conflicts derived from the exposure of domestic livestock to puma Puma concolor predation within ranches in a large, remote region of Patagonia, Argentina. The puma is one of the largest mammalian carnivores of the Americas and is widely distributed from eastern Canada to the steppes of Patagonia in southern Argentina and Chile. In North America, a number of studies have investigated local and regional puma distribution and habitat use in detail (Maehr and Cox 1995, Maehr 1997, Kerkhoff et al. 2000, Logan and Sweanor 2001, Riley and Malecki 2001, Dickson and Beier 2002, Alexander et al. 2006, Kautz et al. 2006). Information derived from those studies has been used to aid large-scale landscape restoration and regional conservation planning (Meegan and Maehr 2002, Root 2004, Kautz et al. 2006). In contrast, little is known about puma habitat use and distribution in South America (Franklin et al. 1999). The species seriously conflicts with livestock activities in that region (Mazzolli et al. 2002, Conforti and de Azevedo 2003, Polisar et al. 2003), however, and thus suffers persecution (Franklin et al. 1999, Mazzolli et al. 2002). Many puma populations in South America have been reduced by hunting (Franklin et al. 1999), and their long-term conservation requires efforts to minimize conflicts between pumas and human activities (Mazzolli et al. 2002, Conforti and de Azevedo 2003).

Patagonian ranchers consider pumas a threat to livestock (especially sheep), and in some Patagonian provinces, ranching associations have provided economic incentives to hunt pumas. The limited information regarding puma ecology in Patagonia is a serious constraint to the development of conservation policies and actions aimed to reduce conflicts with humans and to promote viable puma populations. We provide a first assessment of the spatial risk of livestock exposure to pumas in Patagonian ranches. We developed a rule-based habitat model to predict the potential distribution of puma habitat at a regional scale and analysed its sensitivity to rule values. Second, we used empirical data from Patagonian ranches and tested whether puma records in these conflict areas are associated with our rule-based habitat predictions. Third, we evaluated if characteristics of ranch paddocks (i.e. vegetation cover, topography, and distance to roads) explain puma occurrences within Patagonian ranches. Finally, we simulated three livestock management scenarios and compared the likelihood of livestock exposure to pumas among different husbandry strategies that have been suggested by experts and rangeland managers. We aim to contribute to reconciling sustainable livestock production and puma conservation in Patagonia.

\section{Material and methods}

\section{Study area}

The study area (Fig. 1) is ca $94000 \mathrm{~km}^{2}$ and includes the western portion of the extra-Andean Patagonian steppes in Argentina between 39830?S and 45827?S. It encompasses the Sub-Andean and Occidental district of the Patagonian phytogeographical region (León et al. 1998) and includes the eastern foothills of the Andes Mountains, extra-Andean Sierras, basaltic plateaus, alluvial and glacier valleys and hills. The climate is cold temperate and humid towards the Andes ( $>1000 \mathrm{~mm}$ of annual precipitation) and arid at the eastern extreme (B150 mm of precipitation) (Paruelo et al. 1998). Since the beginning of the 20th century the region has been extensively grazed by sheep Ovis aries (Soriano 1983). Sheep rely on the native vegetation as the sole source of forage and their populations are maintained by the internal replacement of ewes and wethers.

\section{Rule-based habitat predictions}

The first step in our analyses was to predict the spatial distribution of puma habitat on a regional basis. We first defined several habitat rules at the scale of puma home ranges based on an exhaustive revision of published literature on puma ecology. To spatially represent these habitat rules we used a digital land cover classification of the study region based on Landsat TM imagery (acquired 30 December 1997) with a spatial resolution of $30>30 \mathrm{~m}$ (Paruelo et al. 2004). Briefly, the land cover classification was accomplished using a maximum likelihood supervised method based on field vegetation data from $>250$ georeferenced field sites $>1$ ha. This classification recognized 11 different vegetation types including forest, shrubland, bare soils, and several types of steppe. An evaluation using an independent sample showed that vegetation types observed in the field were highly correlated with those predicted by the classification $(\mathrm{r}=0.81, \mathrm{n}=48, \mathrm{p} \mathrm{B} 0.01)$. More details can be found in Paruelo et al. (2004). Habitat rules were translated into a Geographic Information System using Arc/Info v.8.3 (ESRI, Redlands, CA, USA). Finally, to evaluate the effect of the different rule assumptions on habitat predictions we performed an uncertainty analysis including a predefined range of rule parameter values around the reference set (Schadt et al. 2002a).

The habitat selection rules were implemented as follows.

Rule 1: vegetation type. The occurrence of pumas in different areas of its range is closely linked to forests (Maehr and Cox 1995, Maehr 1997, Kerkhoff et al. 2000) or other tall and dense vegetation that provides security cover (Beier 1995, Dickson and Beier 2002). This habitat preference has been confirmed in the Patagonian mountains where pumas are found primarily in areas with high cover of trees and large shrubs (Franklin et al. 1999). Therefore, we reclassified the original land cover map categories "deciduous forests" and "scrublands" as "woody vegetation" (i.e. vegetation $>1.5 \mathrm{~m}$ height; Paruelo et al. 2004) to represent vegetation structure suitable for puma habitat (Fig. 2A). 

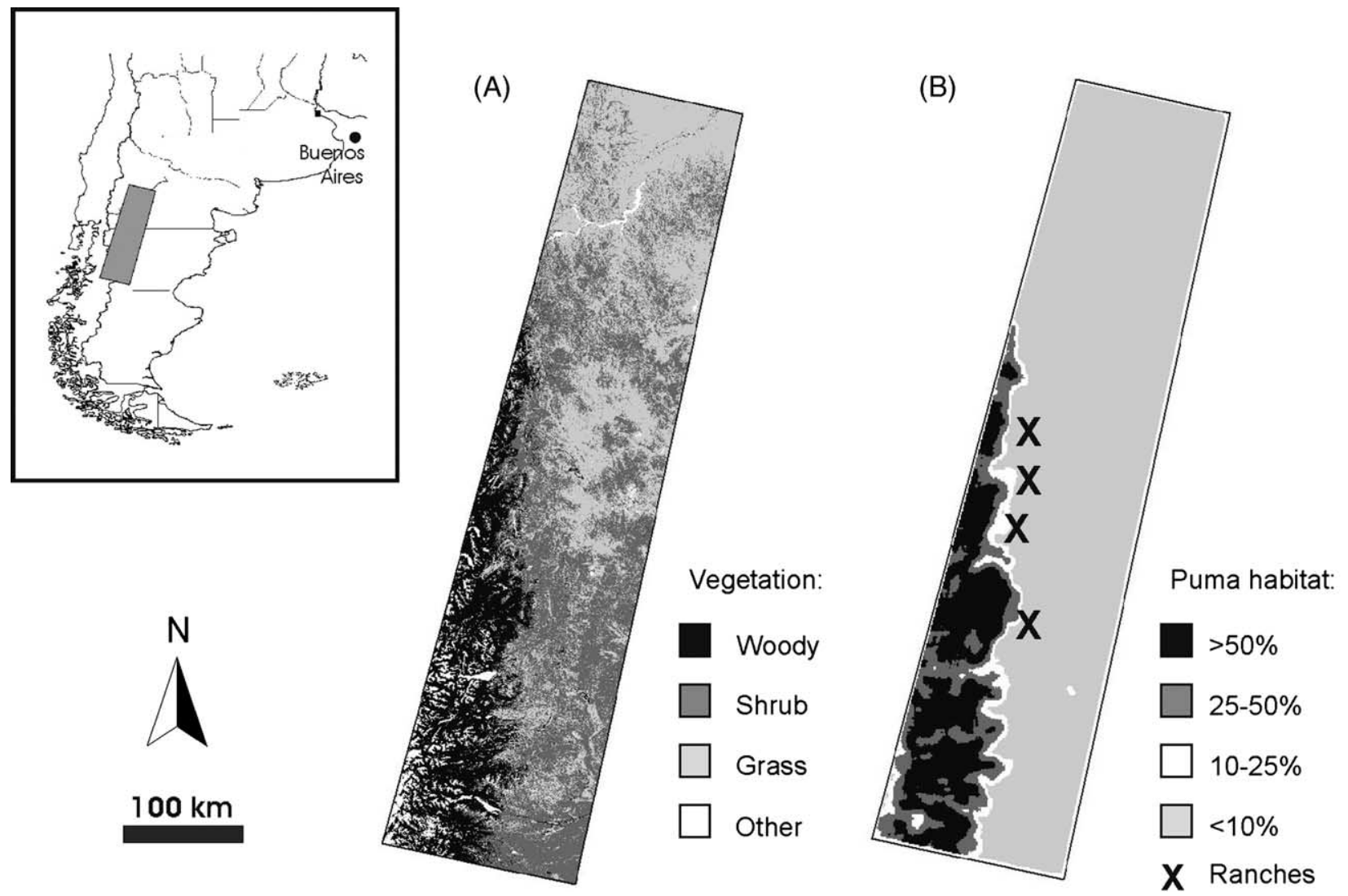

Figure 1. Vegetation and predicted puma habitat in the western portion of the extra-Andean Patagonian steppes, Argentina. (A) Vegetation map showing the ca $94000 \mathrm{~km}^{2}$ study area. Black= woody vegetation patches $>500$ ha; dark grey= shrub steppes; light grey $=$ grass steppes and prairies; white $=$ water, snow and rocks. (B) Predicted puma habitat based on rule-based habitat model. Black $=$ $50-100 \%$ woody vegetation cover in window of $100 \mathrm{~km}^{2}$ size, dark grey $=25-50 \%$ woody vegetation cover, white $=10-25 \%$ woody vegetation cover, light grey $510 \%$ woody vegetation cover (also contains excluded area at the edge of the map), $\mathrm{X}=$ location of ranches.

Since the spatial resolution of the original map was $30 \mathrm{~m}$, woody patches separated by larger distances were spatially unconnected in the derived map. We connected woody vegetation patches within $180 \mathrm{~m}$ distance because pumas frequently move this distance to reach neighbouring forest patches in their daily movements (Maehr and Cox 1995, Root 2004). Application of rule 1 resulted in a map that we refer to as "woody vegetation map" (Fig. 2B).

Rule 2: minimum patch size. Maehr and Cox (1995) found that pumas most often occurred in habitat patches $>500$ ha. We thus excluded patches B500 ha from the woody vegetation map, resulting in a map that we refer to as "500 ha patch map" (Fig. 2C). To evaluate the effect of assuming different minimum patch size requirements on our habitat predictions, we analysed a wider range of minimum patch size assumptions by calculating the differences in area predictions among the woody vegetation map; the 500 ha patch map; and an additional map excluding patches B2000 ha.

Rule 3: home range characteristics. Minimum home range sizes for pumas in South America have been reported to be up to $100 \mathrm{~km}^{2}$ (Franklin et al. 1999). This size is also a good estimate for habitat and carrying capacity estimations in other puma populations (Root 2004). In addition, Kerkhoff et al. (2000) showed that optimal puma home ranges have $125 \%$ forest cover. We implemented both home range characteristics by generating a grid composed of
$1>1 \mathrm{~km}$ cells covering our study region, and determined for each cell how much woody vegetation cover was located in a window of $10>10 \mathrm{~km}$ (i.e. an average puma home range size of $100 \mathrm{~km}^{2}$ ) around each focal $1>1 \mathrm{~km}$ cell. We performed this analysis on the 500 ha patch map for the reference habitat predictions and on the woody habitat map and 2000 ha map for sensitivity analyses. If the window area covered $>25 \%$ of woody vegetation, then the $1>1 \mathrm{~km}$ cell was assigned to puma habitat (Fig. 2D, referred to as "puma habitat map"). Because moving window approaches tend to underestimate habitat area at the edge of the study area, we calculated habitat suitability only for windows that overlapped the land cover map in at least $75 \%$ of their area. To evaluate the uncertainty associated to the definition of home range size, we explored how the $100 \mathrm{~km}^{2}$ assumption affected results by comparison with sizes of $64 \mathrm{~km}^{2}$ (i.e. $8>8 \mathrm{~km}$ size) and $196 \mathrm{~km}^{2}$ (i.e. $14>14 \mathrm{~km}$ size), respectively (compare with Spreadbury et al. 1996, Franklin et al. 1999, Logan and Sweanor 2001, Dickson and Beier 2002). Last, we also assessed the effects of the minimum forest threshold assumption by comparison with thresholds of 10 and $50 \%$, respectively. The uncertainty effects on model predictions was represented as the percent difference in amount of puma habitat predicted for all combinations of minimum patch size suitable for pumas, minimum forest cover within home ranges, and mean home range size. 


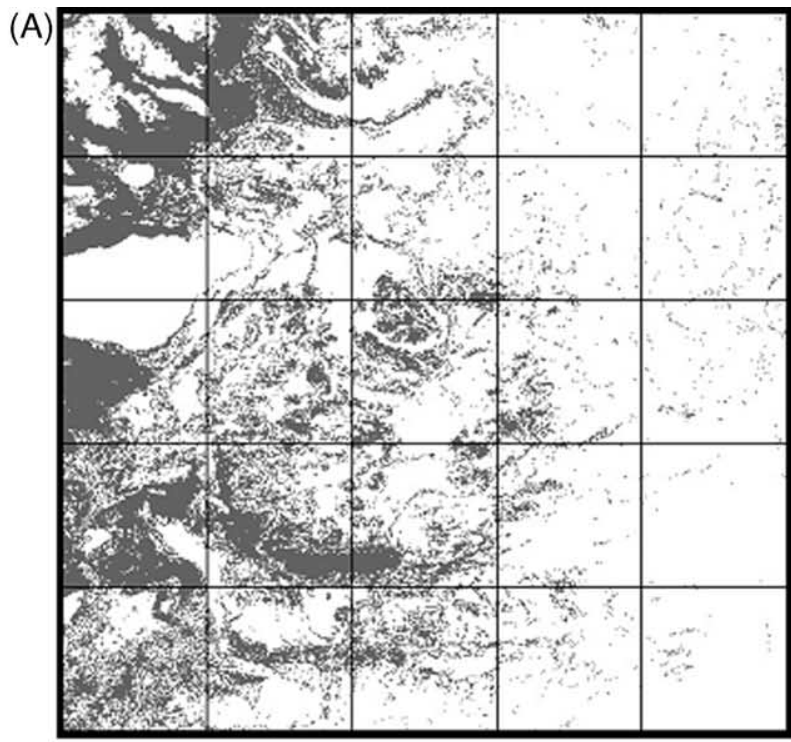

(B)

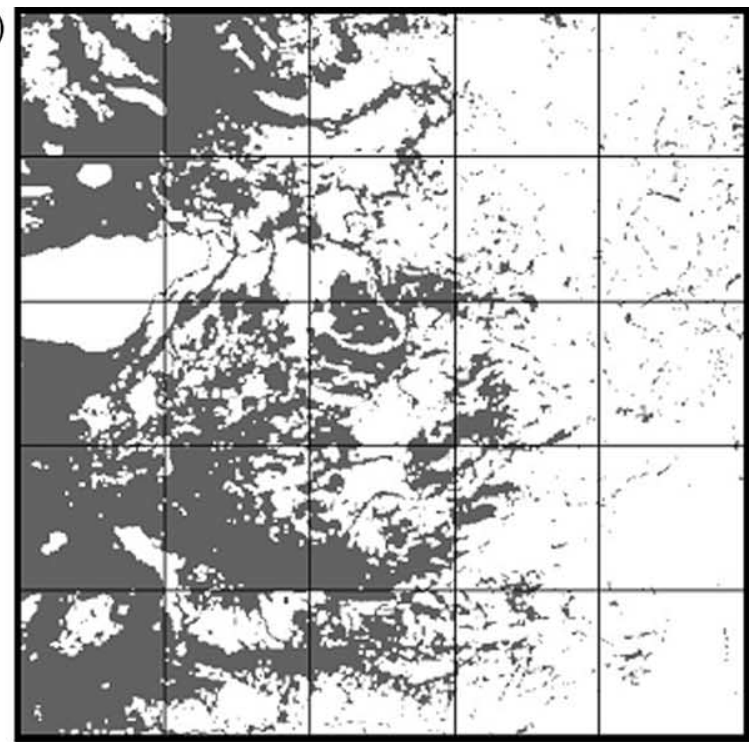

(C)

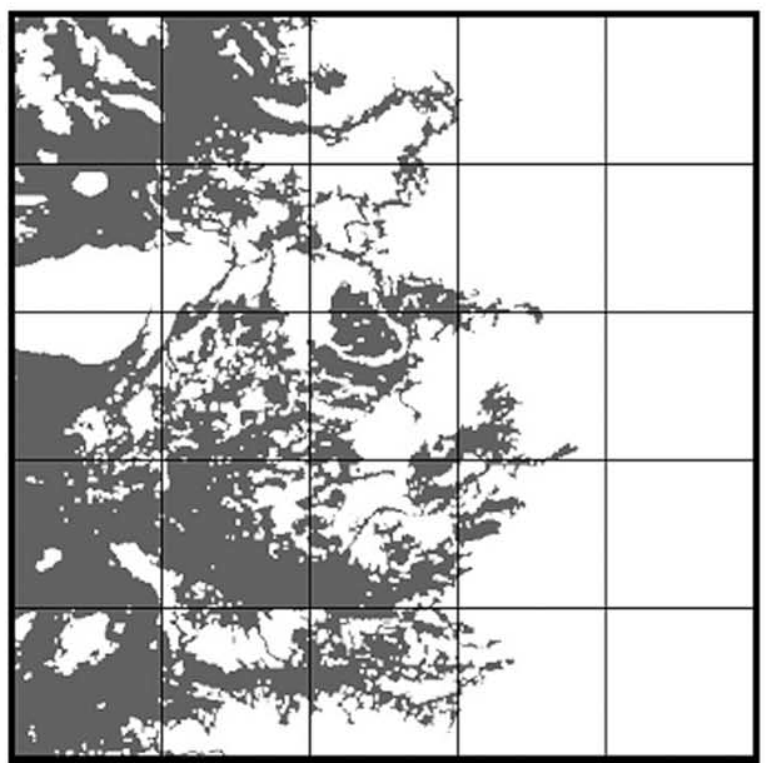

(D)

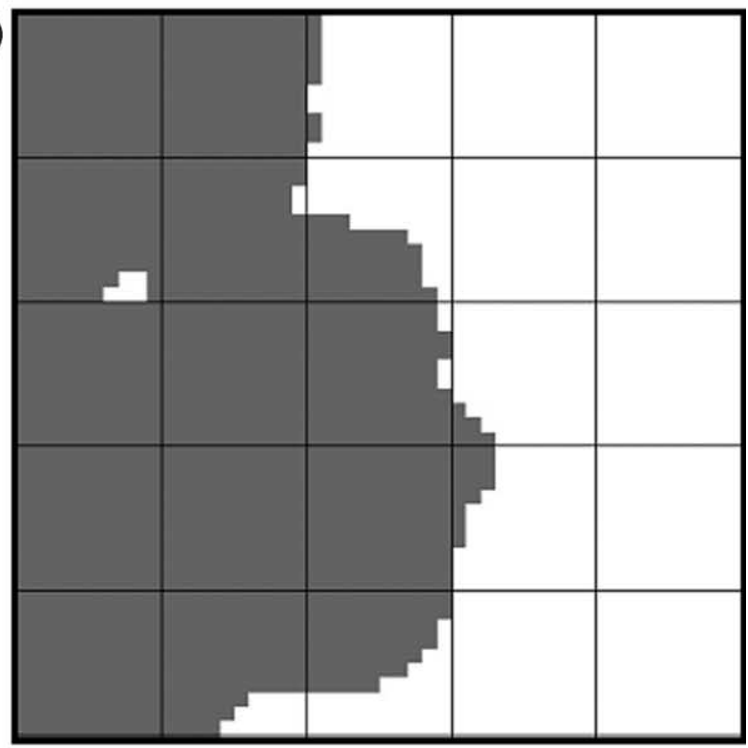

Figure 2. Application of rule set to predict puma habitat, exemplified for a $50>50 \mathrm{~km}^{2}$ area in Patagonia, Argentina. A grid with $10>$ $10 \mathrm{~km}$ cells (i.e. $100 \mathrm{~km}^{2}$ ) is overlaid to illustrate the average size of a puma home range. (A) Original land cover map with woody vegetation (i.e. deciduous forest and scrubland) as derived from remotely-sensed data from Landsat TM images. (B) "Woody vegetation map" where woody vegetation patches (from the original land cover map, see A) B180 m distant are connected (rule 1 only). (C) “500 ha patch map” where woody vegetation patches smaller than 500 ha are excluded (rule 1革2). (D) Predicted puma habitat. For each $1 \mathrm{~km}^{2}$ grid cell the amount of woody vegetation cover (as shown in C) is determined in a window of $10>10 \mathrm{~km}$ size (i.e. an average puma home range size) (rule $1 \neq 2 \neq 3$ ). When woody vegetation in the window is $>25 \%$, a $1 \mathrm{~km}^{2}$ cell is predicted to constitute puma habitat (grey cells).

\section{Puma data}

In a second step, we used records of pumas that were shot on 4 Patagonian ranches (R1-4, Table 1, Fig. 1) to evaluate their consistency with our rule-based predictions of puma habitat. The ranches cover $4704 \mathrm{~km}^{2}$ distributed on a strip parallel to the Andes and are subdivided into paddocks with a mean paddock size of $17-26 \mathrm{~km}^{2}$ (Table 1). Puma records were compiled by ranch administrators from the information and puma corpses provided by ranch-hands who roamed routinely over the paddocks on horseback. The selected ranches have a similar vegetation structure dominated by shrub-grass steppes (Table 1) and share the same sheep management scheme (Golluscio et al. 1998). Puma hunting was a non-focused, occasional activity rewarded by rancher associations and performed by ranch-hands covering similar areas. As a consequence, the distribution of puma hunting effort is similar across all paddocks. Despite the limitations of hunting data for habitat studies, the high data reliability and good coverage of the study area makes our dataset a valuable source of information for model evaluation.

We used hunting records dated from 2000 to 2004 ( $\mathrm{n}=$ 68 pumas) and spatially assigned each event (only where the puma corpse was provided) to one paddock indicating 
Table 1. Vegetation characteristics in 4 study ranches in Patagonia, Argentina.

\begin{tabular}{lcccccc}
\hline Ranch & Size $\left(\mathrm{km}^{2}\right)$ & No. of paddocks & $\begin{array}{c}\text { Paddock size in } \mathrm{km}^{2} \\
(\text { mean 9 SD) }\end{array}$ & & & \multicolumn{2}{c}{ Vegetation type (\%) } \\
\cline { 5 - 7 } & & & & Woody & Shrub steppes & $\begin{array}{c}\text { Grass steppes and } \\
\text { prairies }\end{array}$ \\
\hline R1 & 1075 & 46 & 23.4926 .4 & 12.3 & 61.6 & 25.8 \\
R2 & 1058 & 55 & 19.2921 .2 & 4.0 & 54.0 & 41.4 \\
R3 & 805 & 31 & 26.0924 .3 & 1.5 & 69.5 & 0.3 \\
R4 & 1766 & 104 & 17.0919 .3 & 10.7 & 55.0 & 34.2 \\
\hline
\end{tabular}

puma presence within ranches $(\mathrm{n}=23$ paddocks). By assigning puma locations to paddocks we avoided observer bias in relation to microhabitat selection.

To evaluate whether puma occurrence records were consistent with our rule-based habitat predictions, we calculated the distance of each paddock to the nearest predicted habitat cell with ArcView 3.2 (ESRI, Redlands, CA, USA), using the extension nearest features v. 3.8a (Jenness 2004). For preliminary data exploration, we compared the distances from paddocks occupied by pumas $(n=23)$ to the characteristics of the study area (i.e. all paddocks, $n=190$ ), using Wilcoxon tests. This approach allows exploring patterns in presence-only vs. availability data when true absences cannot be guaranteed (Johnson 1980, Pearce and Boyce 2006). We excluded from these analyses paddocks B300 ha, corresponding to the smallest paddock with a puma record.

We then used puma occurrence records to test the influence of paddock characteristics (vegetation structure, topography, and distance to roads) on puma observations within ranches. As above, we compared characteristics of paddocks with puma records $(\mathrm{n}=23)$ to habitat availability (i.e. all paddocks, $n=190$ ). To analyse differences in vegetation structure we merged the original land cover types (Paruelo et al. 2004) into 3 vegetation classes and calculated their percent cover within each paddock: 1 ) woody vegetation (including "deciduous forest" and "scrubland"), 2) shrub steppes (including all cover types with shrubs, namely "grass-shrub steppes", "shrub-grass steppes", and "shrub steppes"), and 3) grass steppes and prairies (including the cover types "low cover grass steppe", "prairies", "grass steppes", and "semideserts"). Topography was characterized by the mean altitude and the altitudinal range (difference between maximum and minimum altitude) of each paddock from the GTOPO30 digital elevation model provided by the U.S. Geological Survey (Bhttp://edc.usgs.gov/products/elevation/gtopo30/gtopo30. $\mathrm{html}>$ ). To test the effect of roads, we calculated the nearest distance from the edge of each paddock to the next road.

\section{Habitat factors associated to puma records in paddocks}

We developed an information-theoretic model selection procedure (Burnham and Anderson 2003) to test which factors (i.e. rule-based habitat predictions, paddock vegetation structure, topography, and distance to roads) best explained puma records in ranch paddocks. For this, we first designed a set of biologically plausible models representing different hypotheses of increasing complexity on the habitat characteristics associated with puma occurrence on ranches. A priori models included different combinations of habitat variables influencing pumas in other regions and other variables potentially relevant for pumas in Patagonian ranches (Table 4). The habitat characteristics of paddocks with puma observations were compared to randomly selected paddocks representing the available conditions in the study area (Pearce and Boyce 2006). This presence vs availability approach allowed us to avoid assumptions of species absence when information on true absences is not available (Klar et al. 2008). Habitat variables included the predicted distance to suitable habitat based on the rule-based model (DISHAB); proportion of woody vegetation (WOOD), shrub steppes (SHRUB) and grass steppes (GRASS) within the paddock; mean altitude (ALTMEAN) and altitudinal range (ALTRANGE) of the paddock; and the nearest distance from the paddock to the next road (DISROAD). We avoided the inclusion of correlated habitat variables in the same candidate model (all r B0.3). Models were fitted using generalized linear models (GLM) with logit link and binomial error structure (McCullagh and Nelder 1989). To evaluate the likelihood of each candidate model, we designed a Monte Carlo simulation in which we sampled iteratively randomly (with replacement) the same number of puma and availability paddock datasets. Paddocks with $>1$ puma record were weighted by the total number of records to increase their probability of being included in the sample. To guarantee independence among observations, we used puma records from the same paddock only when they were separated by $>1$ month and counted family groups as one record (the total of 68 recorded puma corpses was thus reduced to 54 puma records on 23 paddocks).

In each Monte Carlo simulation, all candidate models were calculated and the model with the lowest $\mathrm{AIC}_{\mathrm{c}}$ was retained as the best model. The $\mathrm{AIC}_{\mathrm{c}}$ is an adjusted Akaike information criterion, which is suitable for situations with low sample sizes in relation to the number of parameters (Burnham and Anderson 2003). We then determined the probability of model selection (p) for each candidate model by calculating the proportion of iterations (from $n=10000$ ) in which a given model was selected. Like Akaike weights (Burnham and Anderson 2003), this measures the estimated inference uncertainty about model selection. Additionally, we quantified in all iterations the differences in $\mathrm{AIC}_{\mathrm{c}}$ between each candidate model and the model with the lowest $\mathrm{AIC}_{\mathrm{c}}$ and then estimated the mean difference across iterations (DAIC ; Burnham and Anderson 2003). We also calculated the mean Nagelkerke pseudo- $\mathrm{R}^{2}$ for each model to evaluate model fit. Last, to evaluate the selected GLM fit to the data we used a method especially designed for presence/availability 
models where the area-weighted frequency of observations in bins is investigated against predicted (GLM) bin ranks (Boyce et al. 2002). A model with good predictive performance would be expected to be one with a strong positive correlation, as higher frequencies of observations would consistently fall within higher GLM bins. Model fitting, simulations, and statistic calculations were all performed using the $\mathrm{R}$ statistical package ( $\mathrm{R}$ Development Core Team 2005).

We compared the risk of livestock exposure to pumas among 3 simulated livestock management scenarios where all paddocks were used for allocating livestock but with different seasonal allocation strategies ("traditional management", "rotational management", and "adaptive management"). The management scenarios were devised assuming that they will support the same stocking rates and, consequently, remove the same amount of forage throughout the year (Soriano and Paruelo 1990, Golluscio et al. 1998, Paruelo and Aguiar 2003). In the traditional management scenario, livestock were distributed among all paddocks year-round. This scenario maximized the spatial dispersion of livestock within a ranch and simulated traditional livestock management (Soriano and Paruelo 1990). In rotational management scenario, livestock were concentrated in a few paddocks for a portion of the year (one season), resulting in high instantaneous stock densities during only one season per year. The seasonal distribution of livestock was aimed to minimize vegetation degradation and desertification. In the adaptive management scenario, minimizing vegetation degradation was still an important objective but additional management constraints were considered to allocate livestock: suitability of paddocks for lambing, rotational restrictions related to livestock requirements, drinking water availability, etc. (Golluscio et al. 1998, Paruelo and Aguiar 2003).

We estimated the relative risk of livestock exposure to puma for each paddock by using predictions from the selected GLM. These values were scaled from 0 to 1 to facilitate comparisons among ranches ("scaled puma exposure"). Puma exposure was mapped using four categories defined by quantiles: very low (1st quantile), low (2nd quantile), medium (3rd quantile), and high (4th quantile). To assess the likelihood of livestock exposure to pumas in each management scenario, we counted the number of seasons (spring, summer, autumn, winter) each paddock was used (i.e. having sheep on it) and then multiplied these numbers by the scaled puma exposure values. Lastly, the resulting values of each paddock were summed up at the ranch level to provide an index of livestock exposure given a certain management scenario. This allowed us to estimate how the spatial and seasonal use of paddocks might affect the relative exposure of livestock to pumas.

\section{Results}

\section{Rule-based habitat predictions}

Nearly twenty-five percent $\left(22695 \mathrm{~km}^{2}\right)$ of the study region in western Patagonia was predicted by the rulebased model to be suitable puma habitat (dark grey and black grid cells in Fig. 1B). Predicted puma habitat was concentrated in the south-western part of this region (Fig.
1B) because most large patches of forests and scrublands are found along the eastern side of the Andes (Fig. 1A).

The uncertainty analysis revealed that alternative scenarios predicted between $19.7 \%\left(18293 \mathrm{~km}^{2}\right)$ and $27.0 \%$ (25 $077 \mathrm{~km}^{2}$ ) puma habitat depending on home range size, minimum amount of forest cover in a home range, and whether 500 ha patches were included or not (Table 2). The greatest uncertainty in habitat predictions resulted from the proportion of vegetation requirements within puma home ranges. For instance, an increase in the minimum woody vegetation cover from 10 to $50 \%$ reduced the amount of predicted puma habitat over more than one fourth (v27-32\%). In contrast, assumptions on minimum woody vegetation patch size to constitute puma habitat did not significantly affect predictions. Also, uncertainty in model rules did not substantially affect the general distribution of predicted puma habitat (Fig. 1B).

\section{Puma occurrence in relation to paddock habitat characteristics}

In general, puma records tended to occur in paddocks with lower distance to the predicted habitat, with a higher proportion of woody vegetation and with more complex topography than expected from availability (Table 3). In contrast, distance to roads and the proportion of shrub steppes, grass steppes, and prairies showed no differences.

When comparing different a priori candidate models of puma occurrence within paddocks, we found that the best models always included the distance to the rule-based predicted habitat (DISHAB) and the paddock altitudinal range (ALTRANGE; Table 4). The best approximating model with the highest selection probability $(\mathrm{p}=0.37)$ included exclusively these 2 variables. Two other competing global models also showed high empirical support ( $\mathrm{p}=$ 0.35 and 0.28 , respectively). However, these two models had only slightly lower mean $\mathrm{AIC}_{\mathrm{c}}$ and $\mathrm{DAIC}_{\mathrm{c}}$ values when compared to the simpler two-predictor model (Table 4). We therefore chose the simpler two-predictor model to assess livestock exposure to puma. Other candidate models, especially single predictor models, had clearly lower support (Table 4). The selected model was parameterized as follows (averaged parameter values across 10000 simulation runs):

$$
\begin{aligned}
\operatorname{logit}(\mathrm{P})= & -1: 77-0: 00014>\text { DISHAB } \neq 0: 00840 \\
& >\text { ALTRANGE }
\end{aligned}
$$

Most recorded puma observations (93\%) were found in medium or high likelihood areas, whereas none of the puma records were located in very low likelihood areas (Fig. 3). Evaluation tests based on bin ranks showed a high correlation between the observed and predicted distribution of puma (Spearman $\mathrm{r}_{\mathrm{s}}=0.86, \mathrm{p}=0.001$ ).

\section{Management scenarios and livestock exposure to pumas}

Our index of livestock exposure to pumas differed among the simulated livestock management scenarios (Fig. 4). 
Puma exposure was highest when livestock were kept at low densities in the paddocks and spatial dispersion was high ("traditional management"). Both "rotational management" and "adaptive management" clearly reduced livestock exposure to pumas in comparison to traditional management (Fig. 4). This was consistent across all ranches. Thus, in our simulations the seasonal rotation of paddock use (applied in "rotational" and "adaptive management") reduced the relative likelihood of livestock exposure to pumas.

\section{Discussion}

Based on remote sensing data and habitat preferences of pumas, our study was the first to examine the distribution of puma habitat for a large, remote area in the southern Hemisphere and the potential factors influencing puma occurrence within Patagonian ranches. Based on the likelihood of puma occurrence in ranch paddocks, we compared the potential risk of livestock exposure to predation among alternative husbandry strategies and identified livestock management scenarios that could help to reduce exposure. Overall, this approach illustrated how habitat models together with simulated livestock management scenarios can be applied to inform mitigation strategies in conflicts between puma conservation and livestock production in South America.

Although the rules in our habitat model are simple and limited by our current understanding of puma habitat and space use, the empirical puma records within Patagonian ranches generally supported predictions based on puma studies in better studied populations. These results showed that the percentage of woody vegetation (including forest and scrubland) at the spatial scale of puma home ranges is a good indicator of the broad-scale distribution of the species habitat. Although spatio-temporal variability in habitat selection has been documented in pumas (Alexander et al. 2006, Beier et al. 2006), the general preference for forests and other tall and dense vegetation is supported by many studies together with avoidance of open vegetation such as grasslands (Beier 1995, Maehr and Cox 1995, Maehr 1997, Kerkhoff et al. 2000, Riley and Malecki 2001, Dickson and Beier 2002, Meegan and Maehr 2002, Dickson et al. 2005, Kautz et al. 2006). Our analyses revealed that other factors additionally require consideration to explain puma occurrence in Patagonia. At the paddock level, steppe vegetation cover and distance to roads had little explanatory power, whereas paddock topography had a notable effect. The altitudinal range of the paddock reflects the spatial heterogeneity of the landscape and its relevance for puma is explained by a higher availability of refuge areas (Riley and Malecki 2001).

The likelihood of puma occurrence within ranches, and thus livestock exposure to predation, were largely associated with landscape characteristics around the livestock production areas. Overall, proximity to forested habitats and topographic heterogeneity seem to be the most important habitat factors determining puma occurrence in Patagonia. Similarly, a study on cattle predation by pumas in a ranch in central-western Brazil reported that $>50 \%$ of pastures with predation events were in close proximity to forest 
Table 3. Comparisons of paddocks with puma records $(n=23)$ with all paddocks constituting the habitat availability sample $(n=190)$. Median, min, and max values and results of 2-sample Wilcoxon tests are given. Habitat was predicted with a rule-based habitat model using 3 different thresholds $(10,25,50 \%)$ to determine the minimum amount of woody vegetation cover in a $10 \mathrm{~km}^{2}$ window around each $1 \mathrm{~km}^{2}$ cell. $\mathrm{W}=$ Wilcoxon test statistic, $\mathrm{p}=$ probability value.

\begin{tabular}{|c|c|c|c|c|}
\hline \multirow[b]{2}{*}{ Variable } & \multicolumn{2}{|c|}{ Median (min-max) } & \multicolumn{2}{|c|}{ Wilcoxon } \\
\hline & Presence & Availability & W & $\mathrm{p}$ \\
\hline \multicolumn{5}{|c|}{ Distance to predicted habitat $(\mathrm{km})$} \\
\hline For $10 \%$ threshold & $0(0-14)$ & $3(0-36)$ & 1784 & 0.142 \\
\hline For $25 \%$ threshold & $5(0-22)$ & $8(0-47)$ & 1673 & 0.065 \\
\hline For $50 \%$ threshold & $9(0-29)$ & $15(0-54)$ & 1716 & 0.093 \\
\hline \multicolumn{5}{|l|}{ rauuock vegetalıorl cover (\%) } \\
\hline Woody vegetation & $6(0-63)$ & $2(0-75)$ & 2673 & 0.081 \\
\hline Shrub steppes & $65(23-98)$ & $66(3-99)$ & 2172 & 0.963 \\
\hline Grass steppes and prairies & $17(1-50)$ & $26(1-93)$ & 1866 & 0.253 \\
\hline \multicolumn{5}{|l|}{ Paddock topography (m) } \\
\hline Mean altitude & 916 (648-1287) & $850(499-1287)$ & 2987 & 0.004 \\
\hline Altitudinal range & $425(54-1108)$ & $157(0-1108)$ & 3317 & 0.000 \\
\hline \multicolumn{5}{|l|}{ Distance to roads $(\mathrm{km})$} \\
\hline Distance to roads & $0(0-9.3)$ & $0(0-9.3)$ & 2358 & 0.501 \\
\hline
\end{tabular}

(Palmeira et al. 2008). Also, analyses on a ranch-wildlife reserve in western Brazil showed that forest proximity was the only variable associated with patterns of livestock mortality, with predation risk increasing as distance to forest declined (de Azevedo and Murray 2007). Analyses from North America further support our results that domestic sheep predation by pumas is best explained by the distribution of puma habitat (Torres et al. 1996).

In addition to landscape constraints, the heterogeneous distribution of native and exotic prey densities may influence puma occurrence within and outside ranches (Yañez et al. 1986, Iriarte et al. 1991, Franklin et al. 1999, Novaro et al. 2000, Alexander et al. 2006). In Patagonia, pumas feed predominantly on introduced wild prey species such as European hares Lepus europaeus, red deer Cervus elaphus, and wild boars Sus scrofa (Yañez et al. 1986, Franklin et al. 1999, Novaro et al. 2000). In most parts of Patagonia, native large-bodied prey species such as guanacos Lama guanicoe, lesser rheas Pterocnemia pennata and plains vizcacha Lagostomus maximus now comprise a relatively small proportion of the biomass available and pumas have shifted from native to exotic prey species (Novaro et al. 2000). Puma may opportunistically respond to changes in prey availability in both space and time (Yañez et al. 1986, Iriarte et al. 1991, Branch et al. 1996, Novaro et al. 2000, Alexander et al. 2006), but how this influences puma

Table 4. Model selection among seventeen a priori candidate models to explain puma observations within Patagonian ranches. Values were estimated from Monte Carlo simulations $(n=10000)$ where the same number of paddocks was randomly sampled (with replacement) from the set of paddocks occupied by pumas and from habitat availability (all paddocks). $\mathrm{AlC}_{\mathrm{c}}=$ bias-adjusted Akaike information criterion; $\mathrm{DAIC}_{\mathrm{c}}=$ difference in $\mathrm{AIC}_{\mathrm{c}}$ between candidate model and model with lowest $A I C_{c} ; p=$ probability of model selection; $R^{2}=$ Nagelkerke $R^{2}$. $\mathrm{AIC}_{c}, \mathrm{DAIC}_{\mathrm{c}}$ and $\mathrm{R}^{2}$ are mean values across 10000 simulations, whereas $\mathrm{p}$ indicates how often a model was best ranked based on $\mathrm{AIC}_{\mathrm{c}}$. Predictors are: $\mathrm{DISHAB}=$ nearest distance from paddock to puma habitat as predicted by the rule-based habitat model; WOOD $=\%$ woody vegetation cover of paddock; SHRUB $=\%$ tall steppe cover of paddock; GRASS $=\%$ low steppe and prairie cover of paddock; ALTMEAN $=$ mean altitude of paddock; ALTRANGE =altitudinal range of paddock; DISROAD $=$ nearest distance of paddock to next road.

\begin{tabular}{lccc}
\hline Models and explanatory variables & $\mathrm{AIC}_{\mathrm{c}}$ & $\mathrm{DAIC}_{\mathrm{c}}$ & $\mathrm{p}$ \\
\hline 1. Null model & & & 0.00 \\
Intercept only & 151.7 & 60.9 & - \\
2. Distance to predicted habitat & & & 0.00 \\
DISHAB & 142.7 & 52.4 & 0.00 \\
3. Paddock characteristics & 144.7 & 53.7 & 0.00 \\
WOOD & 152.6 & 61.8 & 0.00 \\
SHRUB & 144.2 & 53.3 & 0.00 \\
GRASS & 129.4 & 37.5 & 0.00 \\
ALTMEAN & 109.2 & 17.4 & 0.00 \\
ALTRANGE & 151.7 & 60.6 & 0.11 \\
DISROAD & & & 0.28 \\
4. TwO-predictor models & 143.2 & 53.0 & 0.47 \\
DISHAB, SHRUB & 140.0 & 49.5 & 0.03 \\
DISHAB, GRASS & 122.7 & 31.2 & 0.00 \\
DISHAB, ALTMEAN & 95.2 & 3.0 & 0.00 \\
DISHAB, ALTRANGE & 142.9 & 52.5 & 0.13 \\
DISHAB, DISROAD & & & 0.17 \\
4. Global models & 121.6 & 29.4 & 0.35 \\
DISHAB, SHRUB, DISROAD, ALTMEAN & 94.5 & 1.4 & 0.59 \\
DISHAB, SHRUB, DISROAD, ALTRANGE & 121.6 & 0.14 \\
DISHAB, GRASS, DISROAD, ALTMEAN & 94.4 & 29.8 & 0.00 \\
DISHAB, GRASS, DISROAD, ALTRANGE & & 1.6 & 0.35 \\
\hline
\end{tabular}




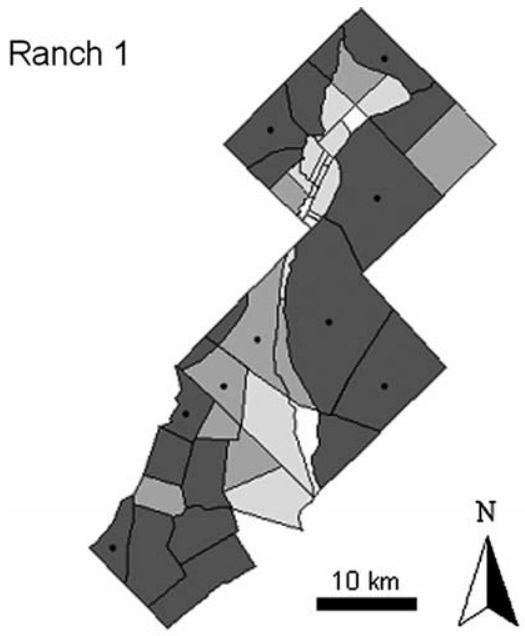

Ranch 3

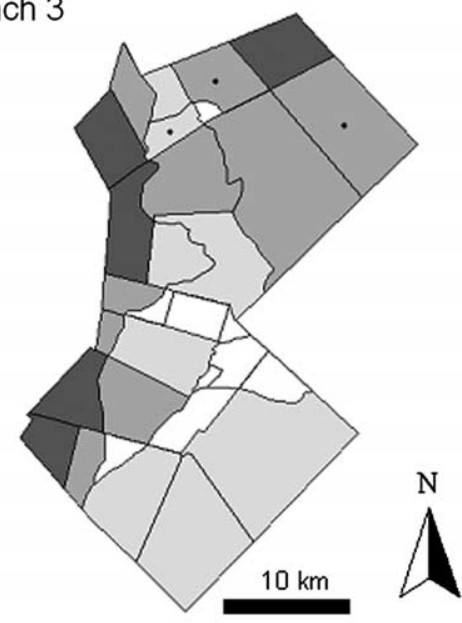

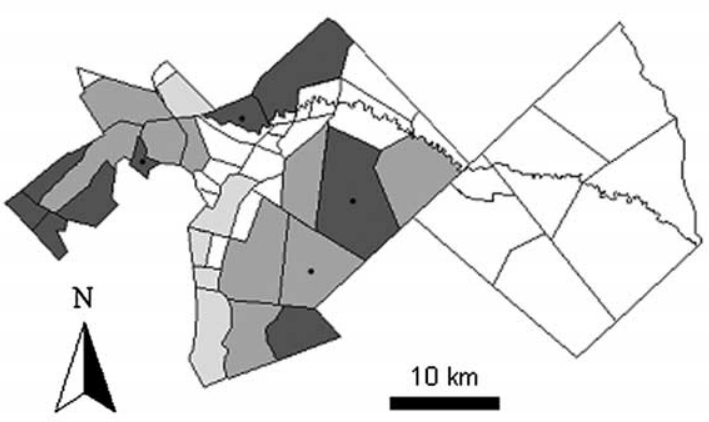

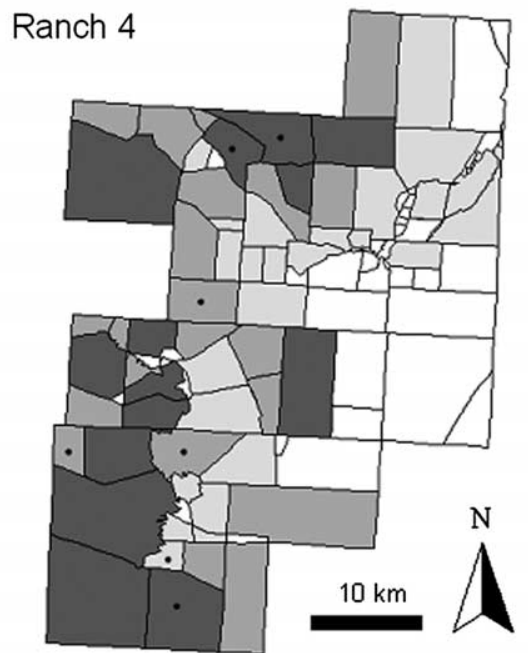

Puma predation risk:

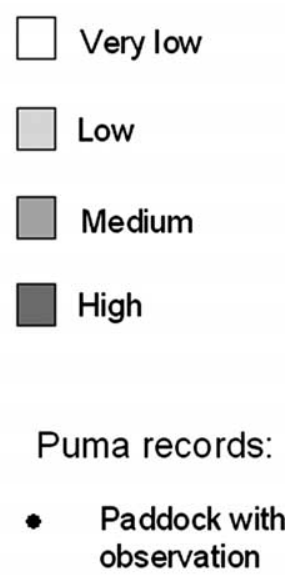

Figure 3. Likelihood of exposure to puma within 4 Patagonian ranches. Probability values were calculated from the selected GLM (eq. 1). Exposure to puma was mapped using 4 categories defined by quantiles: very low (white; 1st quantile, $\mathrm{p}=0-0.028$ ), low (light gray; 2 nd quantile, $\mathrm{p}=0.028-0.086$ ), medium (medium gray; 3rd quantile, $\mathrm{p}=0.086-0.26$ ), and high (dark gray; 4th quantile, $\mathrm{p}=0.26-1$ ). Paddocks with B300 ha size were excluded from the analyses. Black dots denote paddocks where pumas have been recorded in the years 2000-2004.

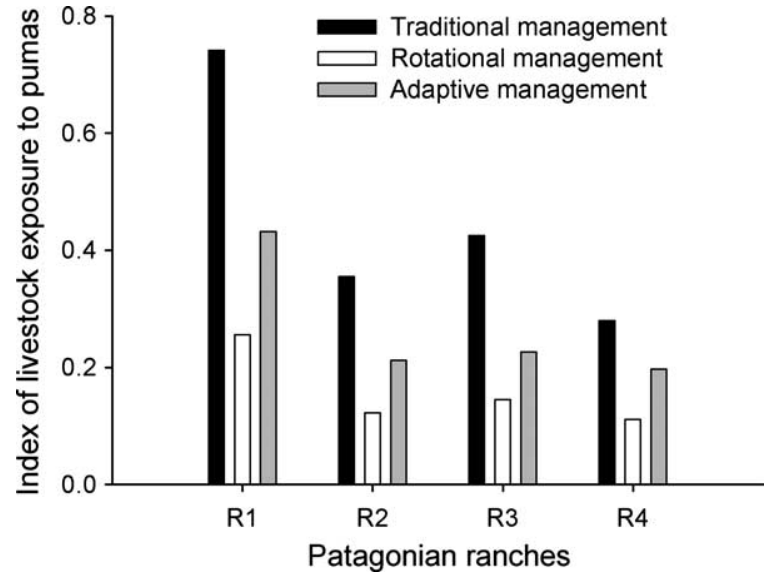

Figure 4. Risk of livestock exposure to pumas for 3 simulated management scenarios (traditional, rotational, and adaptive management) in 4 Patagonian ranches (R1-R4). predation on livestock remains unclear (Novaro et al. 2000, Polisar et al. 2003). Therefore, one of the fundamental issues in future risk assessments is to understand how the distribution of wild prey interacts with landscape composition to determine puma predation on livestock in South America (Franklin et al. 1999, Mazzolli et al. 2002, Polisar et al. 2003, Alexander et al. 2006).

Our risk assessment of livestock exposure to pumas indicated that livestock management strategies could play a key role in reducing the conflict between pumas and ranchers. Simulations showed that livestock management which seasonally rotates the use of paddocks is likely to reduce livestock exposure to pumas, mainly because livestock are allocated less time in those paddocks with a higher exposure to puma. Though livestock density would be higher in some paddocks in rotational livestock management strategies ("rotational management", "adaptive management") than in a continuous, year-round use of paddocks ("traditional management"), there is little evidence that sheep density itself governs puma attraction to paddocks in 
Patagonia. In Patagonian ranches, sheep flocks behave as semi-natural populations (both regionally and at the ranch scale) and are maintained year long in paddocks with minimal control of grazing regime, no forage or nutrient supplementation, and minimal sanitary management (Texeira and Paruelo 2005). Due to the gregarious behaviour of sheep, pumas find relatively large local concentrations of animals even at low stock densities ( $>100$ sheep concentrated on a few hectares). Therefore, the maintenance of certain paddocks without livestock during parts of the year ("rotational management") seems the best strategy to reduce the encounter of pumas and sheep in Patagonia. Currently, the difficulty to confirm the reliability of sheep predation reports limits the formal evaluation of this hypothesis. The future implementation of management strategies to mitigate the carnivore-livestock conflict requires evaluation protocols able to contrast the effect of sheep allocation on puma attacks.

This study thus provides a critical piece of information for managing the conflict between ranchers and pumas in Patagonia: there is room for a "win-win" alternative if a proper grazing and risk management regime is followed. A rotational management strategy, which was originally designed to reduce vegetation degradation (Golluscio et al. 1998), might additionally provide opportunities to reduce sheep depredation by pumas. Managing grazing of native vegetation in a way that minimizes ranch degradation also appears to reduce the exposure of livestock to predators like pumas. A management plan that further increases instantaneous stocking densities (high number of animals per area during a short period of time), that explicitly includes exposure to puma predation and its costs, and/or that replaces livestock species (e.g. sheep by cattle) in high exposure areas (e.g. higher altitude paddocks close to forests) might be best means of reducing the conflict between pumas and ranchers in Patagonia. In this respect, predictions from habitat models have the potential to identify sheep flocks at risk and might help to incorporate both sheep and puma security criteria in ranch management schemes.

While alternative livestock management strategies that explicitly incorporate exposure to puma predation can be implemented immediately in the Patagonian steppes, several knowledge gaps still need to be filled. The future development and validation of models for puma habitat assessment in South America would certainly benefit from more empirical data. Especially needed are more detailed studies on puma occurrence, behaviour, habitat and space use, and livestock predation in South America, both in protected areas and ranches. These data will be helpful to construct more accurate model rules by incorporating movement behaviour of pumas within heterogeneous landscapes (Cramer and Portier 2001, Dickson et al. 2005), minimum habitat requirements and landscape-related factors relevant for puma population dynamics (Beier 1993, 1996, Sweanor et al. 2000, Root 2004), and puma traits influencing livestock predation (Wydeven et al. 2004). Furthermore, research should be directed towards testing and implementing husbandry techniques that have the potential to reduce livestock losses to pumas (Ogada et al. 2003). Our approach is a first step towards reconciling sustainable livestock production and puma conservation in Patagonia and might be more widely applicable to other human-carnivore conflicts when little empirical information is available on the species of interest.

Acknowledgements - We thank M. Delibes, C. F. Dormann, S. M. Alexander and anonymous reviewers for comments on earlier versions of this manuscript, S. Kramer-Schadt and T. Wiegand for constructive discussions, and $\mathrm{M}$. Texeira for help with data collection. We are also grateful to the ranch administrators who provided information on pumas within ranches. N. F. was partly funded by a Marie Curie Host Fellowship provided by the European Commission (HPMDCT-2001-00109). This work was carried out under an agreement between CTSA and CTT and FAUBA and supported on a UBACYT project.

\section{References}

Alexander, S. M. et al. 2006. Spatio-temporal co-occurrence of cougars (Felis concolor), wolves (Canis lupus) and their prey during winter: a comparison of two analytical methods. - J. Biogeogr. 33: 2001-2012.

Beier, P. 1993. Determining minimum habitat areas and habitat corridors for cougars. - Conserv. Biol. 7: 94-108.

Beier, P. 1995. Dispersal of juvenile cougars in fragmented habitat. - J. Wildl. Manage. 59: 228-237.

Beier, P. 1996. Metapopulation models, tenacious tracking, and cougar conservation. - In: McCullough, D. R. (ed.), Metapopulations and wildlife conservation. Island Press, pp. 293323.

Beier, P. et al. 2006. Evaluating scientific inferences about the Florida panther. - J. Wildl. Manage. 70: 236-245.

Boyce, M. S. et al. 2002. Evaluating resource selection functions. - Ecol. Model. 157: 281-300.

Branch, L. C. et al. 1996. Response of pumas to a population decline of the plains vizcacha. - J. Mammal. 77: 1132-1140.

Burnham, K. P. and Anderson, D. R. 2003. Model selection and multimodel inference: a practical information-theoretic approach, 2nd ed. - Springer.

Conforti, V. A. and de Azevedo, F. C. C. 2003. Local perceptions of jaguars (Panthera onca) and pumas (Puma concolor) in the Iguacu National Park area, south Brazil. - Biol. Conserv. 111: 215-221.

Cramer, P. C. and Portier, K. M. 2001. Modeling Florida panther movements in response to human attributes of the landscape and ecological settings. - Ecol. Model. 140: 51-80.

de Azevedo, F. C. C. and Murray, D. L. 2007. Evaluation of potential factors predisposing livestock to predation by jaguars. - J. Wildl. Manage. 71: 2379-2386.

Dickson, B. G. and Beier, P. 2002. Home-range and habitat selection by adult cougars in southern California. - J. Wildl. Manage. 66: 1235-1245.

Dickson, B. G. et al. 2005. Influence of vegetation, topography, and roads on cougar movement in southern California. - J. Wildl. Manage. 69: 264-276.

Fernández, N. et al. 2003. Identifying breeding habitat for the Iberian lynx: inferences from a fine-scale spatial analysis. - Ecol. Appl. 13: 1310-1324.

Fernández, N. et al. 2006. Viability and risk assessment in species restoration: planning reintroductions for the wild boar, a potential disease reservoir. - Ecol. Soc. 11: 6, Bwww.ecology andsociety.org/vol11/iss1/art6/ $>$.

Franklin, W. L. et al. 1999. Ecology of the Patagonia puma Felis concolor patagonica in southern Chile. - Biol. Conserv. 90: 3340.

Golluscio, R. A. et al. 1998. Sustentabilidad y manejo en las estepas Patagónicas. - Ecol. Austral 8: 265-284. 
Graham, K. et al. 2005. Human-predator-prey conflicts: ecological correlates, prey losses and patterns of management. - Biol. Conserv. 122: 159-171.

Iriarte, J. A. et al. 1991. Feeding ecology of the Patagonia puma in southernmost Chile. - Rev. Chil. Hist. Nat. 64: 145-156.

Jenness, J. 2004. Nearest features (nearfeat.avx) extension for ArcView 3.x, v. 3.8a. - Jenness Enterprises, Bwww.jennessent. com/arcview/nearest_features.htm $>$.

Johnson, C. J. et al. 2004. A quantitative approach to conservation planning: using resource selection functions to map the distribution of mountain caribou at multiple spatial scales. - J. Appl. Ecol. 41: 238-251.

Johnson, D. H. 1980. The comparison of usage and availability measurements for evaluating resource preference. - Ecology 61: 65-71.

Kautz, R. et al. 2006. How much is enough? Landscape-scale conservation for the Florida panther. - Biol. Conserv. 130: 118-133.

Kerkhoff, A. J. et al. 2000. Toward a panther-centered view of the forests of south Florida. - Conserv. Ecol. 4: 1, Bwww.ecology andsociety.org/vol4/iss1/art1/>.

Klar, N. et al. 2008. Habitat selection models for European wildcat conservation. - Biol. Conserv. 141: 308-319.

León, R. et al. 1998. Grandes unidades de vegetación de la Patagonia extra andina. - Ecol. Austral 8: 125-144.

Logan, K. A. and Sweanor, L. L. 2001. Desert puma: evolutionary ecology and conservation of an enduring carnivore.- Island Press.

Maehr, D. S. 1997. The comparative ecology of bobcat, black bear, and Florida panther in south Florida. - Bull. Flor. Mus. Nat. Hist. 40: 1-176.

Maehr, D. S. and Cox, J. A. 1995. Landscape features and panthers in Florida. - Conserv. Biol. 9: 1008-1019.

Mazzolli, M. et al. 2002. Mountain lion depredation in southern Brazil. - Biol. Conserv. 105: 43-51.

McCullagh, P. and Nelder, J. A. 1989. Generalized linear models. - Chapman and Hall.

Meegan, R. P. and Maehr, D. S. 2002. Landscape conservation and regional planning for the Florida panther. - Southeast. Nat. 1: 217-232.

Mladenoff, D. J. et al. 1995. A regional landscape analysis and prediction of favourable gray wolf habitat in the Northern Great Lakes Region. - Conserv. Biol. 9: 279-294.

Novaro, A. J. et al. 2000. Ecological extinction of native prey of a carnivore assemblage in Argentine Patagonia. - Biol. Conserv. 92: 25-33.

Ogada, M. O. et al. 2003. Limiting depredation by African carnivores: the role of livestock husbandry. - Conserv. Biol. 17: $1521-1530$.

Packer, C. et al. 2005. Lion attacks on humans in Tanzania understanding the timing and distribution of attacks on rural communities will help to prevent them. - Nature 436: 927928.

Palmeira, F. B. L. et al. 2008. Cattle depredation by puma (Puma concolor) and jaguar (Panthera onca) in central-western Brazil. - Biol. Conserv. 141: 118-125.

Paruelo, J. M. and Aguiar, M. R. 2003. El impacto humano sobre los ecosistemas: el caso de la desertificación en Patagonia. - Ciencia Hoy 13: 48-59.

Paruelo, J. M. et al. 1998. The climate of Patagonia: general patterns and controls on biotic processes. - Ecol. Austral 8: 85-104.
Paruelo, J. M. et al. 2004. Regional scale relationships between ecosystem structure and functioning: the case of the Patagonian steppes. - Global Ecol. Biogeogr. 13: 385-395.

Pearce, J. L. and Boyce, M. S. 2006. Modelling distribution and abundance with presence-only data. - J. Appl. Ecol. 43: 405412.

Polisar, J. et al. 2003. Jaguars, pumas, their prey base, and cattle ranching: ecological interpretations of a management problem. - Biol. Conserv. 109: 297-310.

R Development Core Team 2005. R: a language and environment for statistical computing. - $\mathrm{R}$ foundation for Statistical Computing, Vienna, Austria, Bwww.R-project.org $>$.

Riley, S. J. and Malecki, R. A. 2001. A landscape analysis of cougar distribution and abundance in Montana, USA. - Environ. Manage. 28: 317-323.

Root, K. V. 2004. Florida panther (Puma concolor coryi): using models to guide recovery efforts. - In: Akçakaya, H. R. et al. (eds), Species conservation and management: case studies. Oxford Univ. Press, pp. 491-504.

Schadt, S. et al. 2002a. Rule-based assessment of suitable habitat and patch connectivity for the Eurasian lynx. - Ecol. Appl. 12: 1469-1483.

Schadt, S. et al. 2002b. Assessing the suitability of central European landscapes for the reintroduction of Eurasian lynx. - J. Appl. Ecol. 39: 189-203.

Soriano, A. 1983. Deserts and semi-deserts of Patagonia. - In: West, N. E. (ed.), Temperate deserts and semi-deserts. Elsevier, pp. 423-460.

Soriano, A. and Paruelo, J. M. 1990. El manejo de campos de pastoreo en Patagonia: aplicación de principios ecológicos. - Ciencia Hoy 2: 44-53.

Spreadbury, B. R. et al. 1996. Cougar population characteristics in southeastern British Columbia. - J. Wildl. Manage. 60: 962969.

Stahl, P. et al. 2001. Predation on livestock by an expanding reintroduced lynx population: long-term trend and spatial variability. - J. Appl. Ecol. 38: 674-687.

Starfield, A. 1990. Qualitative, rule-based modeling. - BioScience 40: 601-604.

Sweanor, L. L. et al. 2000. Cougar dispersal patterns, metapopulation dynamics, and conservation. - Conserv. Biol. 14: 798808.

Texeira, M. and Paruelo, J. M. 2005. Demography, population dynamics and sustainability of the Patagonian sheep flocks. - Agric. Syst. 87: 123-146.

Torres, S. G. et al. 1996. Mountain lion and human activity in California: testing speculations. - Wildl. Soc. B 24: 451-460.

Treves, A. and Karanth, K. U. 2003a. Human-carnivore conflict and perspectives on carnivore management worldwide. - Conserv. Biol. 17: 1491-1499.

Treves, A. and Karanth, K. U. 2003b. Special section. Humancarnivore conflict: local solutions with global applications. - Conserv. Biol. 17: 1489-1490.

Treves, A. et al. 2004. Predicting human-carnivore conflict: a spatial model derived from 25 years of data on wolf predation on livestock. - Conserv. Biol. 18: 114-125.

Wydeven, A. P. et al. 2004. Characteristics of wolf packs in Wisconsin: identification of traits influencing depredation. - In: Fascione, N. et al. (eds), People and predators: from conflict to coexistence. Island Press, pp. 28-50.

Yañez, J. L. et al. 1986. Food habits of the southernmost mountain lions (Felis concolor) in South America: natural versus livestocked ranges. - J. Mammal. 67: 604-606. 